\title{
Role of lymphoid organ spheroids in chronic Taura syndrome virus (TSV) infections in Penaeus vannamei
}

\author{
Kenneth W. Hasson ${ }^{1, *}$, Donald V. Lightner ${ }^{2}$, Leone L. Mohney ${ }^{2}$, Rita M. Redman ${ }^{2}$, \\ Brenda M. White ${ }^{2}$
}

'Super Shrimp Group, Disease Management Division, 1545 Tidelands Ave, Suite J, San Diego, California 91950, USA

${ }^{2}$ University of Arizona, Department of Veterinary Science and Microbiology, Tucson, Arizona 85721, USA

\begin{abstract}
Lesion development was documented in Penaeus vannamei juveniles with experimentally induced, chronic phase Taura syndrome virus (TSV) infections, by both routine histology and in situ hybridization, during a $48 \mathrm{wk}$ time course study. Histologically, the defining characteristics of TSV chronicity in $P$. vannamei include the absence of acute phase histological lesions, a low prevalence of ectopic spheroid development, and rapid successive lymphoid organ spheroid (LOS) formation and morphogenesis. Three distinct LOS morphotypes (Types A, B, and C) were identified by light microscopy. The earliest detectable LOS. Type A, appeared to evolve from activated LO tubule phagocytes that had sequestered TSV. The succeeding LOS, Type B, contained necrotic cells that were consistently TSV-positive by in situ hybridization for up to $32 \mathrm{wk}$ following an acute phase infection. These persistent, long-term infections suggested that ISV replication occurred within Type B LOS, and this satisfied the definition of a chronic infection. The terminal Type C LOS were consistently found to be TSV-negative and characterized by cells with condensed basophilic nuclei, a reduction in overall cell size, and progressive atrophy leading to degradation without an inflammatory response. These cellular changes are characteristic of apoptotic cells, suggesting that TSV-infected LOS cells self-destruct, resulting in TSV elimination. TSV infections appear to have 3 potential outcomes: (1) the virus may continue to replicate within LOS cells unchecked, (2) it may be eliminated by LOS cells, or (3) viral replication and elimination may occur concurrently, resulting in persistent infections. Ectopic spheroids were TSV-induced and observed in sites normally occupied by tegmental glands within appendages, suggesting that they developed from either hemolymph-borne phagocytes or fixed phagocytes associated with the gland. We suggest that these cellular masses arise from migrating and/or resident phagocytes transformed in response to chronic viral infections or non-self substances too small for hemocyte encapsulation. The possibility that spheroid development represents an unexplored and significant branch of the cell-mediated immune response of penaeid shrimp is discussed
\end{abstract}

KEY WORDS: Taura syndrome virus (TSV) P Penaeid shrimp - Lymphoid organ - In situ hybridization Apoptosis - Picornaviridae Immune response

\section{INTRODUCTION}

Taura syndrome virus (TSV), a deadly infectious disease of the Pacific white shrimp Penaeus vannamei (Perez-Farfante \& Kensley [1997] recommend the genus be changed to Litopenaeus), was first identified

\footnotetext{
·E-mail: hasson@primenet.com
}

in 1994 (Hasson et al. 1995, 1999a,b, Brock et al. 1995, 1997, Lightner et al. 1995a) and is currently classified as a possible member of the Picornaviridae (Bonami et al. 1997). The TSV disease cycle was recently redefined through histological and gene probe analysis of experimentally infected, specific-pathogen-free (SPF) $P$. vannamei that were sampled at timed intervals. It consists of 3 overlapping, clinically and histologically distinct phases: $\mathrm{a} \sim 7 \mathrm{~d}$ peracute to acute phase, $\mathrm{a} \sim 5 \mathrm{~d}$ 
transition phase, and a definitive chronic phase (Hasson et al. 1999b). Following a lethal acute phase infection, surviving $P$. vannamei enter a brief transition phase during which acute phase cuticular epithelial lesions resolve, resulting in the formation of grossly visible melanized lesions on the head and tail of the affected shrimp. In situ hybridization analysis during the transition phase shows that the virus is detectable within a few remaining cuticular epithelial lesions, within sheath cell walls of morphologically normal lymphoid organ (LO) tubules and/or within newly developed masses called LO spheroids (LOS). Termination of the TSV transition phase and entry into the chronic phase is marked by ecdysis and a return to normal feeding and swimming behavior. The rapid development of LOS with intense, focal TSV-positive probe signals by in situ hybridization was deemed the principal hallmark of chronic phase TSV infections (Hasson et al. 1999b).

There are few published morphological and physiological studies on the LO and LOS, and they are briefly reviewed here. The LO is a bi-lobed network of arterioles usually referred to as tubules. It receives hemolymph from the heart via paired afferent vessels branching from the subgastric artery (Oka 1969, Bell \& Lightner 1988). Hemocyte passage through tubule walls into intertubular hemal sinuses has been documented (Martin et al. 1987). The LO is considered an integral part of the penaeid shrimp circulatory system and thought to function as a hemolymph filter (Oka 1969, Bell \& Lightner 1988).

Bonami et al. (1992) found that LOS were commonplace and had been observed within at least 7 different penaeid shrimp species (Penaeus vannamei, P. monodon, $P$. penicillatus, $P$. esculentus, $P$. stylirostris, $P$. chinensis, $P$. merguiensis). In the first anatomical description of shrimp LO, Oka (1969) described 'reticularlike' and 'lymph-like' cells (hemocytes) as principal LO tubule components. Kondo et al. (1994) described the LO as possessing 2 primary components, 'arteriolar tubules' or 'sheathed arterioles' (LO tubules) and 'nodular structures with many vacuolated cells' (LOS) that they considered to be 'senile or degenerating phase' LO tubules. In contrast, analysis of LOS enzymatic activity by Anggraeni (1999) and Anggraeni \& Owens (1998) indicated that LOS are comprised of spent hemocytes that have aggregated within LO hemal sinuses. They also stated that LOS cells display a high apoptotic index.

Ultrastructural analysis (Kondo et al. 1994) indicated that a major LO constituent was a unique cell type morphologically similar to highly phagocytic, dendritic reticulum cells found in mammalian lymphoid follicles. To analyze phagocytic capability, Kondo et al. (1994) and Takahashi et al. (1995) injected colloidal carbon, horseradish peroxidase and FITC-latex beads into Penaeus japonicus and found that these substances were first detectable within LO tubule walls with concurrent onset of LOS development. After injection (1 to $3 \mathrm{mo}$ ), the foreign substances were localized within LOS. LO phagocytic ability was corroborated in ridgeback prawns Sicyonia ingentis by injection of radiolabeled Bacillus subtilus (Martin et al. 1996). Within 15 min post-injection, and by both light and electron microscopy, the majority of the bacteria were phagocytosed and localized within LO tubule cells. These findings showed that LO tubules and LOS removed biotic and abiotic substances from the shirmp circulatory system by phagocytosis

LOS development has also been associated with at least 6 different penaeid shrimp viral infections: (1) lymphoid organ vacuolization virus (LOVV, Bonami et al. 1992), (2) lymphoidal parvo-like virus (LPV, Owens et al. 1991), (3) lymphoid organ virus (LOV, Spann et al. 1995), (4) rhabdovirus of penaeid shrimp (RPS, Nadala et al. 1992), (5) yellow head virus (YHV, Flegel et al. 1992), and (6) TSV (Hasson et al. 1995, 1999b. Hasson 1998). By light and electron microscopy, Owens et al. (1991) found that LOS of LPV-infected Penaeus monodon contained multinucleate giant cells, hypertrophied nuclei, marginated chromatin, and increased cytoplasm to nuclear volumetric ratios. This cellular transformation was considered anaplastic, but occurred in the near absence of detectable mitotic figures. As these cells became more vacuolated, increased cellular debris was observed. The description of LOS in experimentally RPS-infected P. stylirostris (Nadala et al. 1992) was very similar, but the LOS were referred to as proliferative centers of hyperplastic cells. Indeed, the morphology of LOS induced by all 6 viruses mentioned above is virtually identical, suggesting that LOS development is a general penaeid shrimp response to viral agents.

The primary objective of the present study was to utilize both routine histological techniques and in situ hybridization analysis to document chronic phase TSV lesion development in experimentally infected Penaeus vannamei juveniles. The specific aims of the study were to determine what tissues of the chronically infected shrimp contained detectable TSV, to document TSV-induced LOS development, and to determine the duration of a chronic phase TSV infection.

\section{MATERIALS AND METHODS}

Experimental design. A total of 181 SPF Penaeus vannamei juveniles ( $4.5 \mathrm{~g}$ avg wt), originating from the Oceanic Institute, Hawaii, and reared according to the methods of Wyban et al. (1992) and Pruder et al. (1995), 
were utilized. Prior to initiating the study, 5 shrimp were randomly selected from the test population and preserved for histological analysis to verify their SPF status. Following the methods of Hasson et al. (1995), each test shrimp was administered a single injection, in the third tail segment, of a crude TSV-positive tissue homogenate $\left(\sim 10 \mu \mathrm{lg}^{-1}\right.$ or $\left.45 \mu \mathrm{l}\right)$ that was prepared from frozen TSV-infected $P$. vannamei (Courtesy of $\mathrm{Mr}$ Albert Bennett, Aqualarvas, Sonora, Mexico). The shrimp were then returned to a 1500 l fiberglass tank containing recirculating, biofiltered artificial seawater (32 ppt, 28 to $30^{\circ} \mathrm{C}$ ) (Forty Fathoms Biocrystals Marinemix, Marine Enterprises International Inc., Baltimore, MD). One week post-injection (PI), 88 surviving shrimp $(47 \%)$ remained in the tank. Sampling of the TSV survivors at timed intervals started on Day 4 PI for samples in the transition and early chronic phases of a TSV infection and continued over a $48 \mathrm{wk}$ period as follows: 3 shrimp $w \mathrm{k}^{-1}$ during Weeks 1 to $12 ; 2$ shrimp $w^{-1}$ during Weeks 13 to $16 ; 2$ shrimp $w^{-1}$ in Weeks $20,24,28$, and 32; and 1 shrimp wk ${ }^{-1}$ in Weeks 40 and 48. The number of shrimp sampled per time period was gradually reduced to extend the study to $48 \mathrm{wk}$. The test shrimp were maintained on a pelleted ration (Rangen $35 \%$ ), fed ad lib once per day for the duration of the study.

Histopathology and in situ hybridization analyses. Following the methods of Bell \& Lightner (1988), the samples were preserved with Davidson's AFA (acetic acid, formalin, alcohol) solution, the cephalothorax of each shrimp was midsagitally bisected, and the half displaying the most prominent portion of the lymphoid organ was embedded in paraffin. Cephalothoraxic appendages were not removed so that ectopic spheroids could be observed. From the paraffin blocks, 4 to $5 \mu \mathrm{m}$ consecutive sections of each sample were prepared. One section per sample was collected on a polyL-lysine coated slide (Sigma, St. Louis, MO) for routine histological analysis and the corresponding parallel section on a silane-coated slide (Silane-Prep, Sigma) for in situ hybridization analysis (Hasson et al. 1997. 1999a,b). Sections for routine histology were stained with Mayer-Bennett hematoxylin-eosin phloxine following standard methods (Bell \& Lightner 1988, Lightner 1996). In situ hybridization analyses were performed using a 1:1 mixture of $2 \mathrm{TSV}$-specific, digoxigenin (DIG) labeled cDNA genomic probes (Hasson et al. 1997, 1999a,b, Mari et al. 1998). The gene probed shrimp sections were counter-stained with Bismarck brown, coverslipped, and examined by brightfield microscopy (Lightner 1996). In situ hybridization analysis of the shrimp samples demonstrated that the only tissue types that were TSV-infected were the LO tubules, LOS and/or ectopic. The observed gene probe signals were qualitatively graded from 0 to 4 according to a modified grading system of Bell \& Lightner (1987) and Hasson et al. (1995). Briefly, absence of a TSV gene probe signal was graded as 0 ; mild, focal signals were graded as 1; moderate, locally extensive to multifocal probe signals were assigned a grade of 2 to 3 ; and numerous multifocal to diffuse signals were assigned a grade of 4 . Overall infection severity per shrimp was assigned based on the single tissue or region that displayed the most extensive gene probe signals.

\section{RESULTS}

Peak mortality among the 181 shrimp occurred on Day 2 PI. Shrimp with grossly visible melanized lesions (transition-phase infections) were first observed on Day 3 PI and were detected up through Day 9. By Day 7 , severe acute phase mortalities had ceased, the majority of the shrimp had molted, and 88 shrimp remained in the tank. Fifty-six of the 88 TSV survivors were sampled over a $48 \mathrm{wk}$ period and a steady, lowgrade die-off during the study resulted in a loss of 32 shrimp $\left(\sim 2\right.$ to 3 shrimp $\left.\mathrm{mo}^{-1}\right)$.

\section{Lymphoid organ histopathology}

Routine histological analysis of 5 shrimp from Day 0 showed that they contained no detectable infections or LOS. Fifty-five of the 56 TSV-challenged shrimp displayed spheroids within their LO, which appeared hypertrophied upon gross examination at the time of dissection. With the exception of 6 shrimp $(10 \%)$, which displayed ectopic spheroids within the maxillipeds, paragnath and/or the tips of the periopods, no other histological abnormalities were observed in these samples. The LOS appeared as well delineated, spherical to irregularly-shaped masses of hypertrophied cells, which were interspersed among morphologically normal LO tubules and displayed varying degrees of vacuolization and varying numbers of necrotic cells.

The size of the LOS masses was highly variable, ranging between 50 and $150 \mu \mathrm{m}$ in diameter. Microscopic review of all 56 samples from TSV-challenged shrimp showed that the LOS underwent progressive morphological changes over the course of the study. Three distinct histological LOS morphotypes were identified, which are hereafter referred to as Types $A$, $B$, and $C$ (Table 1). The earliest, Type A (Fig. 1A,B), was characterized by a lightly basophilic, homogeneous cell mass containing few or no necrotic cells or cell debris. The cytoplasm to nuclear volumetric ratio ranged from $\sim 2: 1$ to $3: 1$. Type $B$ spheroids (Fig. $1 C$ to $F$ ) appeared to evolve from Type $A$, but differed by dis- 
Table 1. Penaeus vannamei. Prevalence and severity of lymploid organ spheroid (LOS) morphotypes and total numbers of LOS-positive test shrimp by routine hematoxylin and eosin (H\&.E) histology during 3 intervals over the total observation period of $48 \mathrm{wk}$. Explanations for the morphotypes (Types $A$ to $C$ ) and severity grades (G0 to $\mathrm{G} 4$ ) are given in the 'Materials and methods'

\begin{tabular}{|c|c|c|c|c|}
\hline Sample & $\begin{array}{l}\text { Interval } 1 \\
\text { (Weeks } 1-5)\end{array}$ & $\begin{array}{c}\text { Interval } 2 \\
\text { (Weeks 6-16) }\end{array}$ & $\begin{array}{c}\text { Interval } 3 \\
\text { (Weeks } 20-48 \text { ) }\end{array}$ & Total \\
\hline No of shrimp & 19 & 27 & 10 & 56 \\
\hline \multicolumn{5}{|l|}{ Tyре A } \\
\hline No. positive & 18 & 22 & 6 & 46 \\
\hline$\%$ positive & 95 & 81 & 60 & \\
\hline Severity grade & $\mathrm{G} 1-\mathrm{G} 3$ & $G 1-G 2$ & G1 & \\
\hline \multicolumn{5}{|l|}{ Type B } \\
\hline No. positive & 15 & 27 & 9 & 51 \\
\hline$\%$ positive & 79 & 100 & 90 & \\
\hline Severity grade & $\mathrm{G} 1-\mathrm{G} 2$ & $\mathrm{G} 1-\mathrm{G} 3$ & $\mathrm{G} 1-\mathrm{G} 2$ & \\
\hline \multicolumn{5}{|l|}{ Type C } \\
\hline No positive & 4 & 25 & 10 & 39 \\
\hline$\%$ positive & 21 & 93 & 100 & \\
\hline Severity grade & G1 & $\mathrm{G} 1-\mathrm{G} 2$ & $\mathrm{G} 1-\mathrm{G} 2$ & \\
\hline \multicolumn{5}{|l|}{ Overall LOS } \\
\hline No. shrimp with LOS & 18 & 27 & 10 & $55^{\check{c}}$ \\
\hline$\%$ shrimp with LOS & 95 & 100 & 100 & \\
\hline Severity grade & $\mathrm{G} 1-\mathrm{G} 4$ & $\mathrm{G} 1-\mathrm{G} 3$ & $\mathrm{G} 1-\mathrm{G} 3$ & \\
\hline \multicolumn{5}{|c|}{$\begin{array}{l}\text { This total is less than the sum of the } 3 \text { morphotypes because some LO } \\
\text { contained more than } 1 \text { LOS morphotype }\end{array}$} \\
\hline
\end{tabular}

Histological examination of $56 \mathrm{TSV}$ challenged shrimp over a period of $48 \mathrm{wk}$ revealed that 2 to 3 morphotypes could be seen together in the LO throughout the period of observation (Table 1). However, based on the relative prevalence of the 3 LOS morphotypes (Table 1), observations could be divided into 3 general intervals: 1 to 5 wk post challenge (Interval 1); 6 to 16 wk post challenge (Interval 2); and 20 to 48 wk post challenge (Interval 3). During Interval 1, Type A LOS dominated $(95 \%)$ while Types B $(79 \%)$ and C $(21 \%)$ were less prevalent. During Interval 2, the prevalence of all 3 LOS types was high and roughly equal ( 81 to $100 \%$ ). During Interval 3, Type C (100\%) had the highest prevalence while Types B (90\%) and A $(60 \%)$ were lower. There was also a general change in the severity of the LOS types from Intervals 1 to 3 . The severity of Type A was highest during Interval 1 and lowest during Interval 3, while the reverse was true for Type C. Type $B$ gave maximum severity during Interval 2. The trends for change in morphotype severity were matched by changes in positive hybridization with a TSV probe (Table 2), so that the number of probe-positive Type A LOS was 63\% at Interval 1 and $0 \%$ at Interval 3 , while the number of probe-positive Type C LOS was $0 \%$ at Interval 1 and $10 \%$ at Inter- playing increased numbers of necrotic cells/debris and few to moderate numbers of cytoplasmic vacuoles. The final LOS morphotype, Type C, displayed an overall increase in basophilia, contained highly basophilic nuclei $\sim 33$ to $50 \%$ smaller than those observed in the Type A and B forms, a reduced cytoplasm to nuclear volumetric ratio (ranging from $-0.5: 1$ to $1: 1$ ) and few to numerous cytoplasmic vacuoles (Fig. 1G,H).

The progression from LOS morphotype Type $A$ to Type $C$ was determined based on their sequential appearance in the time course sampled shrimp (Table 1) and by the observation of intermediate or transitional LOS forms, which were defined as LOS containing the characteristics of 2 distinct morphotypes (Fig. 2). In order to quantify the 3 LOS morphotypes and establish a time frame during which each type was observed, the prevalence of LOS per section was qualitatively graded on a scale from 0 to 4 ; (G0) no detectable LOS, (G1) LOS comprising $<25 \%$ of the organ, (G2) LOS comprising -25 to $50 \%$ of the organ, (G3) LOS in -50 to $75 \%$ of the organ, and (G4) LOS in $>75 \%$ of the organ (Table 1). Utilizing this same grading system, an overall LOS severity grade was determined for each shrimp sample.
Table 2. Penaeus vannamei. Prevalence and severity of TSV-probe-positive LOS morphotypes by in situ hybridization analysis during 3 intervals over the total observation period of $48 \mathrm{wk}$. Explanations for the morphotypes (Types A to C) and severity grades (GO to G4) are given in the 'Materials and methods'

\begin{tabular}{|c|c|c|c|c|}
\hline $\begin{array}{l}\text { Sample } \\
\text { No of shrimp }\end{array}$ & $\begin{array}{c}\text { Interval } 1 \\
\text { (Weeks 1-5) } \\
19\end{array}$ & $\begin{array}{c}\text { Interval } 2 \\
(\text { Weeks } 6-16) \\
27\end{array}$ & $\begin{array}{c}\text { Interval } 3 \\
\text { (Weeks 20-48) } \\
10\end{array}$ & Total \\
\hline Type A & & & & \\
\hline $\begin{array}{l}\text { No. TSV-probe + } \\
\% \text { TSV probe + }\end{array}$ & $\begin{array}{l}12 \\
63\end{array}$ & $\begin{array}{l}2 \\
7\end{array}$ & $\begin{array}{l}0 \\
0\end{array}$ & 14 \\
\hline $\begin{array}{l}\text { Type B } \\
\text { No. TSV probe + } \\
\% \text { TSV probe }+\end{array}$ & $\begin{array}{l}14 \\
74\end{array}$ & $\begin{array}{l}24 \\
89\end{array}$ & $\begin{array}{r}7 \\
70\end{array}$ & 45 \\
\hline $\begin{array}{l}\text { Type C } \\
\text { No. TSV probe + } \\
\% \text { TSV probe + } \\
\text { Severity grade }\end{array}$ & $\begin{array}{l}0 \\
0\end{array}$ & $\begin{array}{l}0 \\
0\end{array}$ & $\begin{array}{r}1 \\
10\end{array}$ & 1 \\
\hline $\begin{array}{l}\text { Overall pooled } \\
\text { No. TSV probe + } \\
\% \text { TSV probe + } \\
\text { Severity grade }\end{array}$ & $\begin{array}{c}18 \\
95 \\
\mathrm{G} 1-\mathrm{G} 4\end{array}$ & $\begin{array}{c}24 \\
89 \\
\mathrm{G} 1-\mathrm{G} 3\end{array}$ & $\begin{array}{c}7 \\
70 \\
\mathrm{G} 1-\mathrm{G} 2\end{array}$ & $49^{\mathrm{d}}$ \\
\hline
\end{tabular}




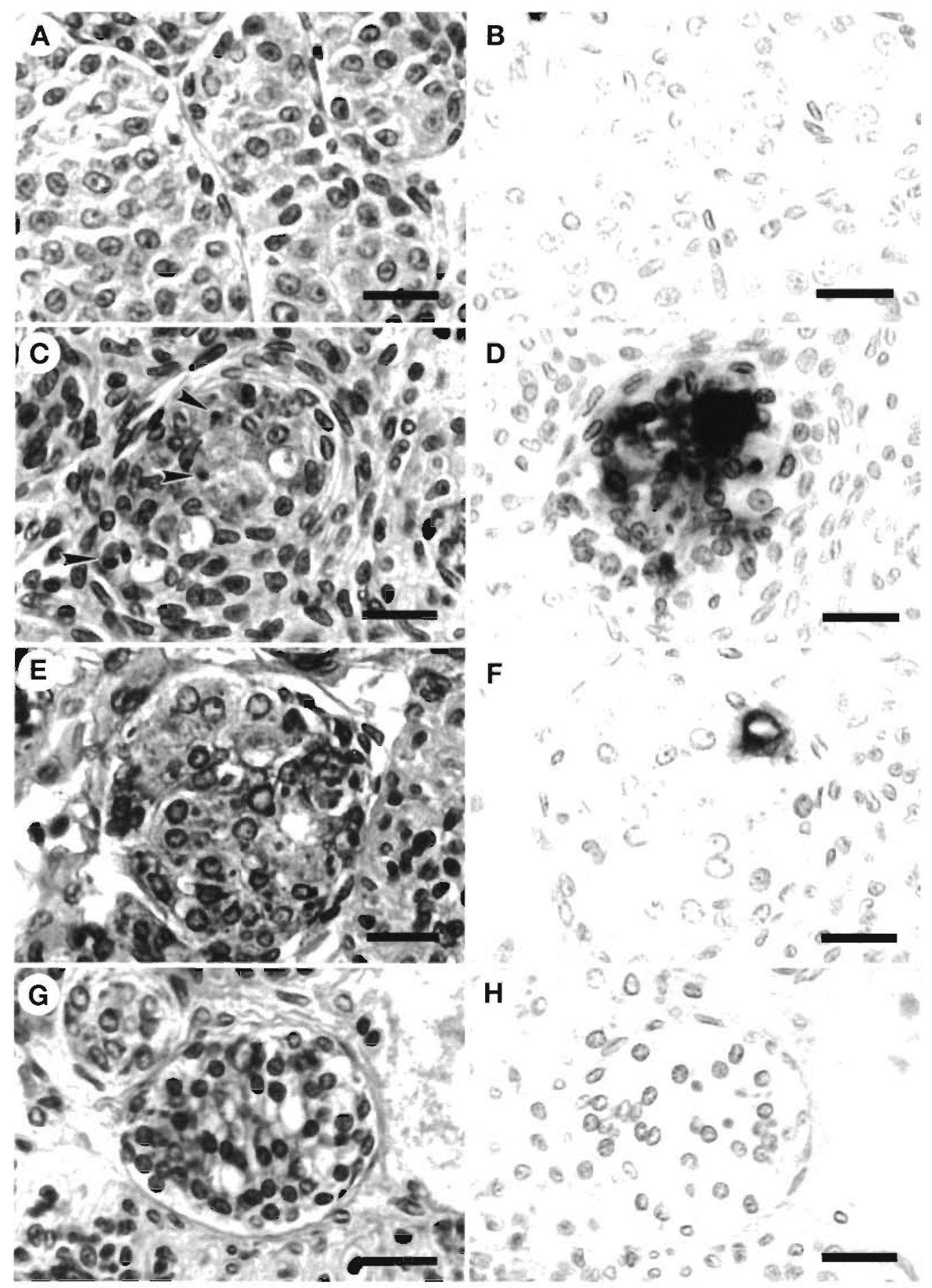

Fig. 1. Penaeus vannamei. Photomicrographs of consecutive H\&E-stained (left column) and gene probed (right column) lymphoid organ (LO) tissue sections illustrating 3 LO spheroid (LOS) morphotypes (Types A to C) from chronic phase TSV infections: (A,B) Type A LOS in a specimen collected $5 \mathrm{wk}$ post-injection (PI). Note the homogeneous appearance of each cell mass, which are gene probe negative. (C,D) Early Type B LOS from a specimen 7 wk PI showing vacuolization (white circles) and the presence of necrotic cells with pyknotic nuclei (arrowheads). A portion of a normal tubule is located to the immediate right of the LOS. Note the strong TSV-probe-positive signal (black precipitate). (E,F) Late Type B LOS from a specimen 32 wk PI displaying increased vacuolization, necrotic cell remnants and increased nuclear basophilia as a result of chromatin margination. A portion of a normal LO tubule is located to the immediate right. Note the focal TSV-probe-positive signal. (G,H) Type C LOS from a specimen 9 wk PI showing condensed, basophilic nuclei and a high degree of cytoplasmic vacuolization. A portion of a normal LO tubule is located immediately below the LOS. Scale bars $=20 \mu \mathrm{m}$ 


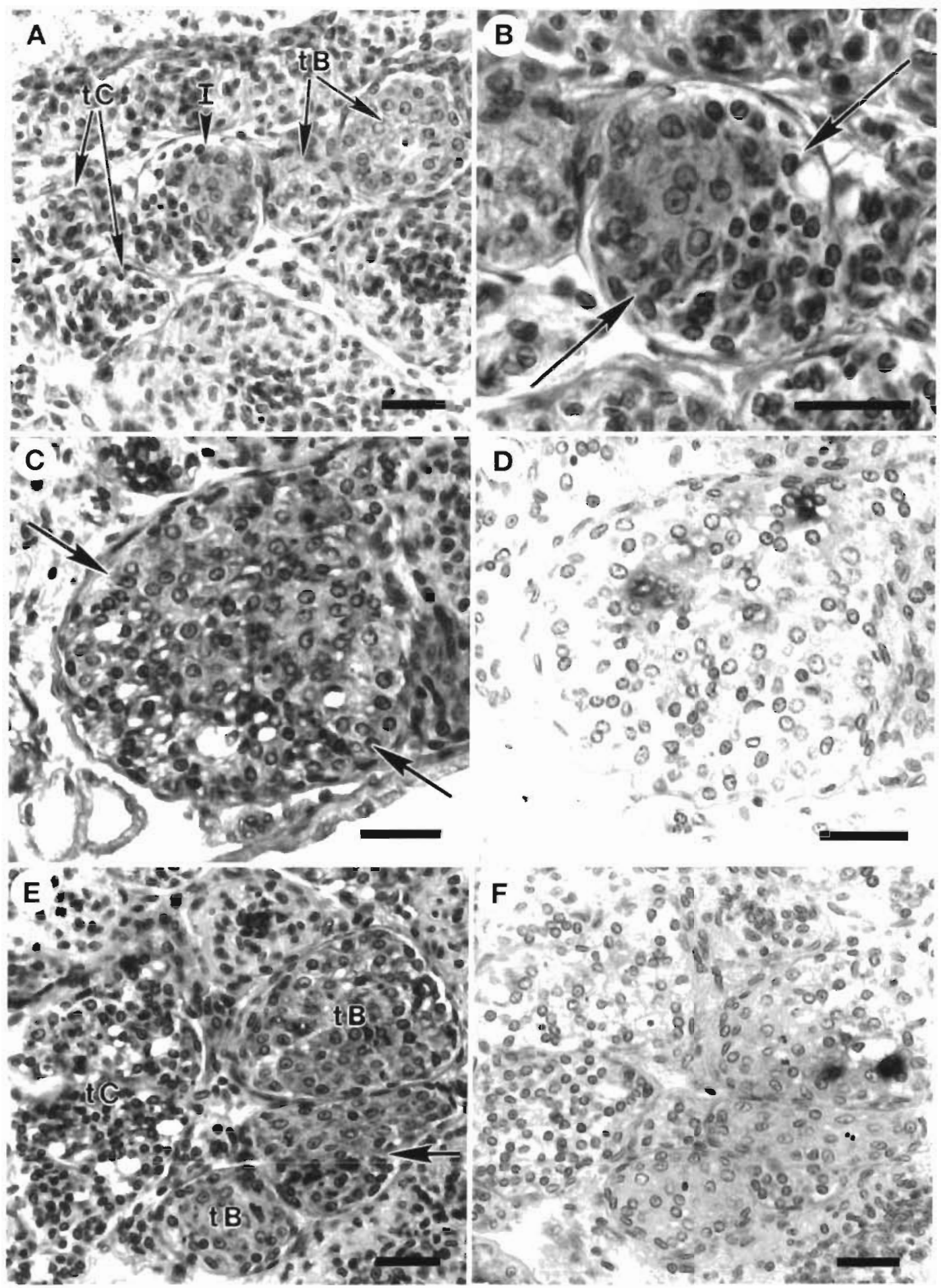

Fig. 2. Penaeus vannamei. Photomicrographs illustrating intermediate forms of LOS. (A) H\&E-stained section from a shrimp 9 wk PI illustrating 2 early Type B LOS (tB), 2 Type C LOS ( $\mathrm{tC}$ ), and an intermediate-form LOS (I) displaying characteristics of both Types $B$ and $C$. Two normal LO tubules can be seen in the lower right corner. (B) High magnification of the intermediate LOS seen in (A). The upper half of the LOS resembles an early Type B LOS, and the lower half a Type C LOS. Arrows in (B) and (C) indicate the line of division between the Type B and Type $C$ portions of the intermediate LOS forms. (C) H\&E-stained and (D) gene probed parallel sections showing another intermediate-form LOS with the top half resembling a late Type B spheroid, and the bottom half a Type C LOS. A gene probe-positive signal is detectable within the Type B portion. (E) H\&E-stained and (F) gene probed parallel sections illustrating an intermediate LOS (arrow) together with 1 Type C LOS (tC) and 2 Type B LOS (tB). The intermediate form shows early Type B morphology at the top and Type C morphology at the bottom. The larger Type B LOS 1s TSV-probe-positive. Scale bars $=30 \mu \mathrm{m}$ 
val 3. The number of probe-positive Type B LOS was high (70 to $89 \%$ ) throughout the period of observation.

During Interval 3, Type C LOS appeared atrophied and in a state of degeneration, and normal tubules predominated in the LO (Fig. 3). When Type C LOS degeneration occurred in the absence of Type $A$ and Type B LOS, it was interpreted as the terminal stage of a chronic phase TSV infection.

\section{Lymphoid organ in situ hybridization}

Forty-nine of the 56 samples assayed demonstrated the presence of TSV within the LO (Table 2). Forty-five of the 49 TSV-positive samples (92\%) demonstrated focal TSV-positive probe signals within Type B LOS (Fig. 1D,F), while $14(29 \%)$ contained focal signals in the Type A morphotype (not shown), and 1 sample $(2 \%)$ contained a single, probe-positive Type C LOS (not shown). Nine samples displayed a diffuse probe signal within morphologically normal LO tubules. TSV-probe-positive signals were detected within LOS in representative samples from each collection period up through Week 32, but they were not observed in the 2 samples collected during Weeks 40 and 48 .
In contrast to the large numbers of LOS observed, the overall probe signal severity was relatively low in the majority of the samples (G1 to G2, Table 2). Probe signals were most numerous (G2 to G4) in samples collected within the first 3 wk PI and least numerous in samples collected during Weeks 24 through 48. In the majority of the TSV-positive LOS, probe signals were confined to LOS sites that contained necrotic cells (e.g. pyknotic nuclei and cytoplasmic eosinophilia) and they were both intense and focal. Some of the necrotic cells appeared to be inside vacuoles, possibly as the result of phagocytosis by adjacent LOS cells.

Comparison of parallel histological and gene probe sections demonstrated the presence of 3 distinct TSV probe signal patterns within the LO of 13 shrimp collected between Weeks 1 to 3 PI (Fig. 4). The LO of 1 shrimp (Day 4) contained no detectable LOS, but displayed a strong diffuse TSV gene probe signal within morphologically normal LO tubules (Fig. 4A,B). Eight other samples produced weak diffuse signals within histologically normal LO tubules together with strong focal signals within some of the LOS that were observable in each shrimp LO (Fig. 4C,D). The 5 remaining samples collected between Weeks 1 and 3 demon-

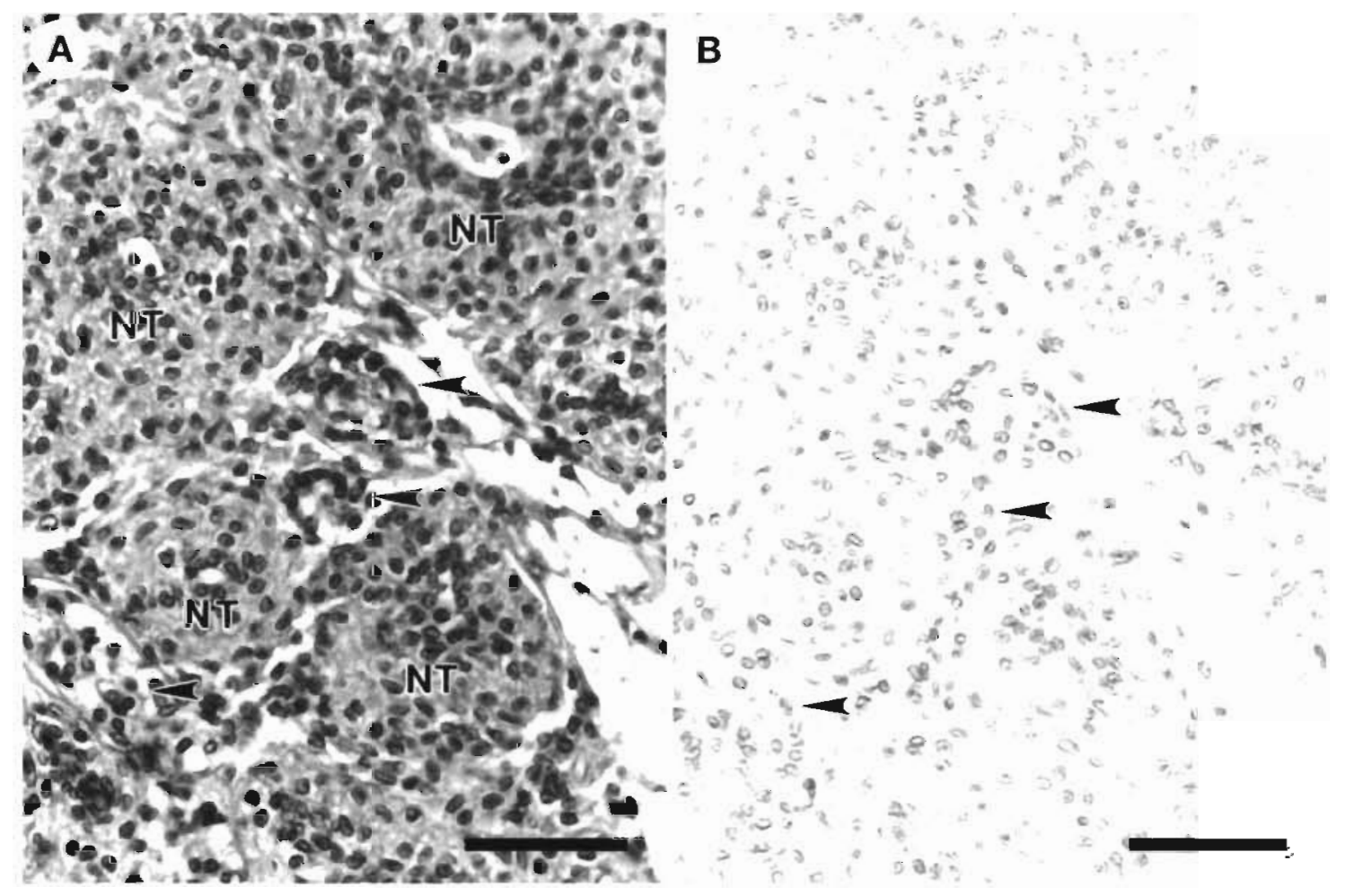

Fig. 3. Penaeus vannamei. Photomicrographs of LO tissue sections illustrating the possible terminal stage of LOS development. (A) H\&E-stained and (B) gene probed LO tissue from a shrimp 40 wk PI showing a few atrophied Type C LOS (arrowheads), -50 to $75 \%$ smaller than those normally seen. Normal LO tubules (NT) surround the Type C LOS. The section is TSV-probenegative. Scale bars $=50 \mu \mathrm{m}$ 


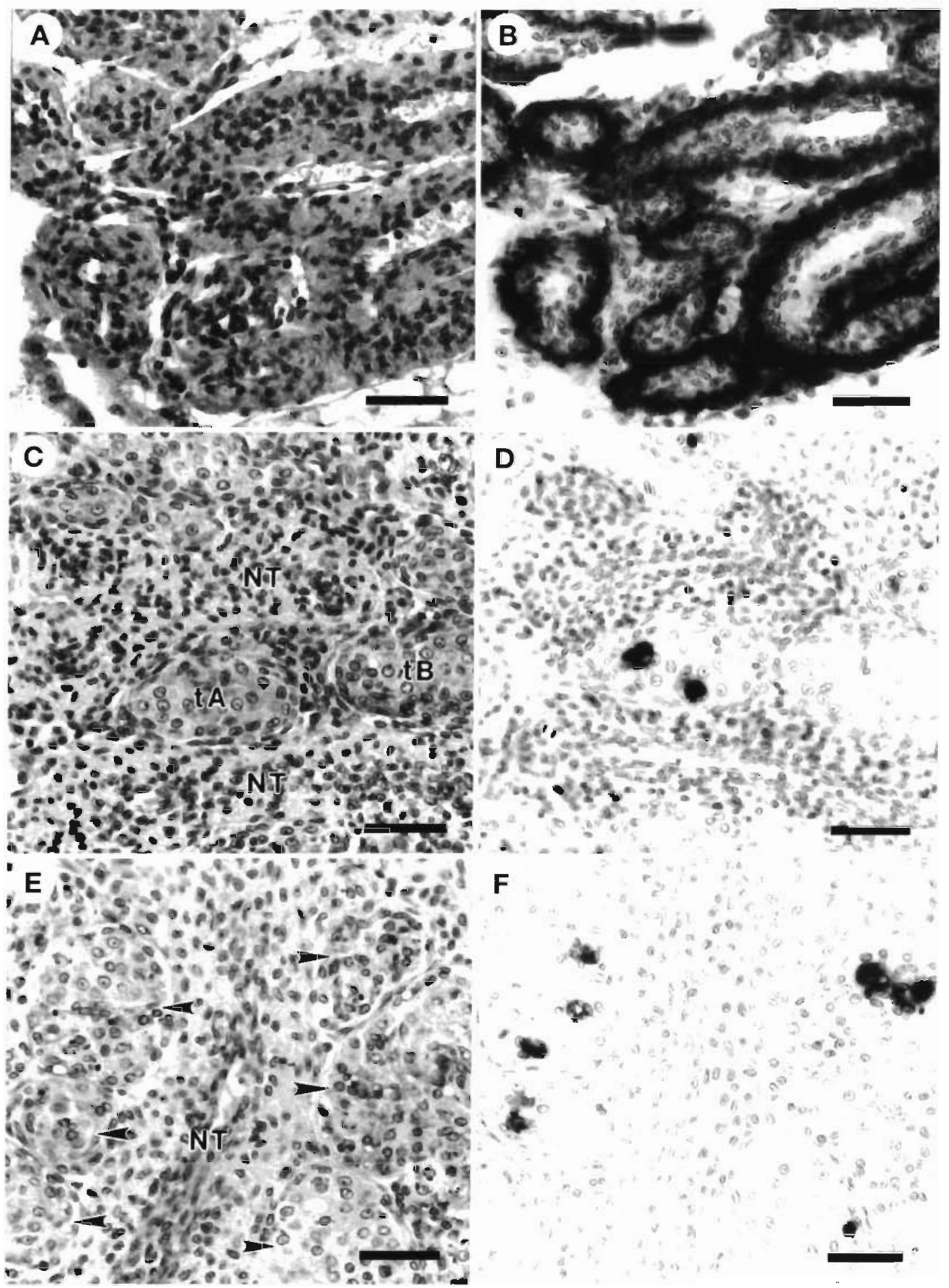

Fig. 4. Penaeus vannamei. Photomicrographs of consecutive H\&E-stained (left column) and gene probed (right column) LO tissue sections illustrating 3 patterns of TSV gene probe signals from chronically infected $P$. vannamei juveniles. $(A, B)$ Pattern from an early transition phase TSV infection where LO tubules appear normal but give a strong positive TSV gene probe signal within the peripheral sheath cells as indicated by the heavy black precipitate. (C,D) Pattern observed in shrimp collected 1 to 3 wk following an acute phase TSV infection showing a late Type A LOS ( $\mathrm{A}$ ), an early Type B LOS (tB) and 2 transversely cut, morphologically normal LO tubules (NT). Two strong focal TSV probe signals can be seen within the Type A spheroid and weak, dispersed signals within the walls of both LO tubules. (E,F) Pattern from an intermediate- to late-stage chronic phase TSV infection showing a normal LO tubule (NT) bordered on each side by 3 Type B LOS (arrowheads). Focal TSV gene probe signals can be seen within the LOS, but there is no signal within the normal LO tubules. Scale bars $=40 \mu \mathrm{m}$ 
strated probe-positive signals within LOS only. Similarly, of the remaining 43 samples collected after this period, 36 displayed probe-positive signals within LOS only (Fig. 4E,F). A single sample, collected during Week 5, displayed the mixed (dispersed plus focal probe signal) pattern similar to that observed in the 8 samples from Weeks 1 through 3.

Six of the 56 shrimp analyzed displayed ectopic spheroids ( $10 \%$ prevalence), which were observed in the paragnath, maxillipeds or periopod tips. In each case, the spheroids were located in sites that are normally occupied by tegmental glands (Fig. 5A,C) and no evidence of spheroid metastases (i.e. LOS migration into other tissues) was observed. Two of the 6 samples displayed strong focal TSV-positive probe signals within Type B ectopic spheroids (Fig. 5D). Each of the 6 samples originated from different sampling intervals $(1,2$, and 3) so no correlation was found between infection interval and ectopic spheroid development.

\section{DISCUSSION}

Based on the results of the current study and previous findings of Hasson (1998) and Hasson et al. (1995, $1999 \mathrm{~b})$, the histological characteristics of chronic phase TSV infection in experimentally infected Penaeus vannamei can be defined. They include the complete absence of acute phase histological lesions of the cuticular epithelium, a low prevalence of ectopic spheroid development, LO hypertrophy directly resulting from the rapid proliferation of numerous LOS, and successive LOS morphogenesis. Clinical features of a chronic-phase TSV infection include a resumption of normal behavioral patterns, absence of disease signs, and an apparent cessation of TSV-induced mortality (Hasson et al. 1999b).

Shrimp in the late transition phase of TSV infection and in the first 2 to 3 wk of a chronic phase TSV infection show diffuse TSV-positive probe signals within morphologically normal LO tubules together with some TSV-positive LOS (Fig. 4). Since LO tubules appear to be unaffected by TSV during the acute infection phase, this suggests that TSV probe signals within morphologically normal LO tubule walls indicate active sequestering of the virus. During this phase, there is an observable increase in the number of Type A LOS and a decrease in the number of TSV-probepositive LO tubules, which might suggest that LO tubules transform into Type A LOS. However, based on findings that LOS consist of aggregated hemocytes (Anggraeni \& Owens 1998, Anggraeni 1999), it may be that resident LO tubule phagocytes sequester TSV and then migrate into the intertubular hemal sinuses, where they aggregate to form LOS. If so, the decrease in number of normal LO tubules may only be a perception resulting from the dispersion of tubules within a hypertrophied LO that contains numerous LOS. Observations of numerous LOS surrounding the subgastric artery in Penaeus vannamei and $P$. stylirostris, with either naturally occurring or experimentally induced chronic TSV infections, support this later hypothesis (Hasson unpubl. data). However, further work is needed to determine which of these 2 hypotheses, or a combination thereof, is valid.

The 3 distinct lymphoid organ morphotypes identified (Types A, B and C) appeared to represent a developmental series. The series began with Type A (homogeneous cell masses) which were found to be probepositive $29 \%$ of the time (14 of 49 , Table 2), suggesting that TSV was either undetectable in the remaining $71 \%$ or was eliminated by an unknown mechanism during spheroid development. The probe-positive Type A LOS then appeared to undergo focal TSVinduced necrosis and nuclear pyknosis with concurrent vacuole formation to produce Type B LOS. Increased vacuolization and nuclear condensation of Type B LOS resulted in Type C LOS, which were devoid of necrotic cell debris. Histologically, the Type B LOS was the most abundant morphotype and also displayed the highest prevalence of TSV-positive probe signals by in situ hybridization, suggesting ongoing viral replication that resulted in LOS cell destruction. The final morphotype, Type C LOS, dominated during the last 20 wk of the study (Table 1) and. typically, gave negative TSV probe results (Table 2).

In brief, LOS numbers appear to increase and transform from Type A to Type C along with a concurrent, but gradual decrease of detectable TSV within the LO. This supports the hypothesis that the LO and LOS play some role in the elimination of invading pathogens, including viruses, by phagocytosis (pinocytosis). LOS morphologically resemble foreign-body-type giant cells formed in mammals by activated resident or migrating macrophages (epitheloid cells) during a chronic inflammatory response (Cotran et al. 1989). The lack of cytoplasmic membranes observed within LOS and the suggestion of giant-cell formation by Owens et al. (1991) further support this possibility. Furthermore, as with other chronic inflammatory infections, the present findings indicate that the response may or may not be successful in eliminating a TSV infection.

Two possible competing processes may occur within the LO during a chronic TSV infection (Fig. 6). In one of these, sequestered TSV may continue to replicate within Type B LOS, successfully escape the LOS, enter the circulatory system and eventually return to the LO, where it would be removed by normal LO tubules. Thus the cycle of LOS morphogenesis could begin 


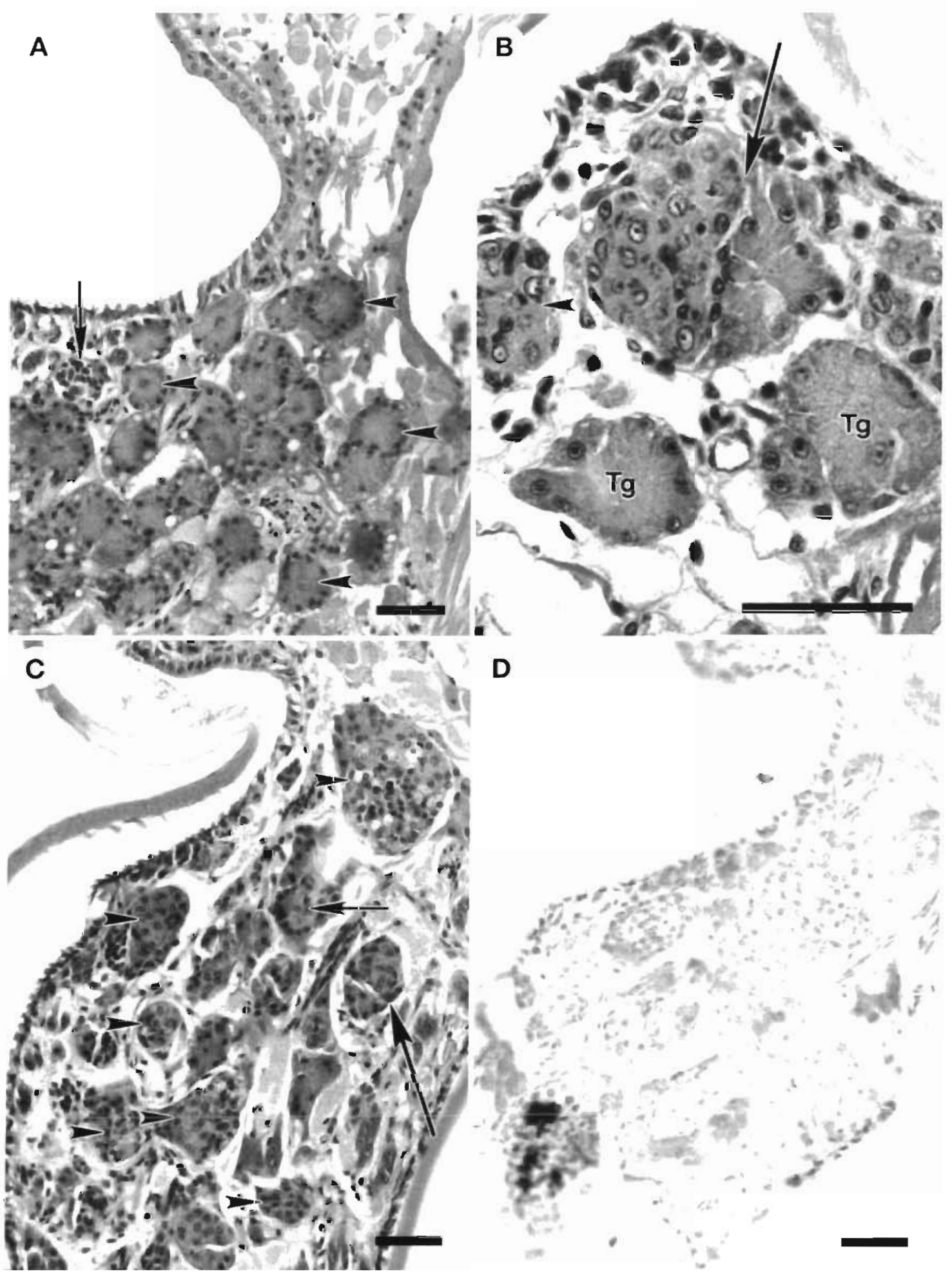

Fig. 5. Penaeus vannamei. Photomicrographs of ectopic spheroids within the third maxilliped of $P$. vannamei juveniles chronically infected with TSV. (A) An H\&E-stained section showing morphologically normal tegmental glands (arrowheads) and a single ectopic spheroid (arrow). (B) High magnification showing 2 normal tegmental glands ( $\mathrm{Tg}$ ), a single ectopic spheroid (arrowhead) and an intermediate form (arrow) which is normal on the right side but contains an early Type B spheroid on the left side. (C) Numerous ectopic spheroids (arrowheads) in foci that previously contained tegmental glands (small arrow). A single intermediate form, similar to that seen in (B), is also apparent (large arrow). (D) Gene probe analysis of a parallel section of (C) shows that one of the spheroids in this maxilliped is TSV-positive, as indicated by the black precipitate. Scale bars $=50 \mu \mathrm{m}$ 
anew and a chronic phase infection could persist in a cyclic fashion. This process could explain the consistent presence of TSV-probe-positive Type B LOS together with 1 or 2 other LOS morphotypes within the LO of most test shrimp, and the reported presence of infectious TSV in hemolymph of chronically infected Penaeus vannamei for up to 1 yr PI (Dr Jeff Lotz \& Bonnie Poulos pers. comm.).

The second possible process is that LOS morphogenesis may progress to Type $C$, and the virus may either be eliminated or its numbers sufficiently reduced to be undetectable by gene probe analysis. The fact that Type C LOS were TSV-probe-negative supports this contention. However, the mechanism of viral elimination is unclear. Since cells of Type C LOS are reduced in size, TSV-probe-negative and elicit no inflammatory response during degradation, they resemble apoptotic cells (Thompson 1995) and it is possible that their selfdestruction results in the elimination of TSV. Examples of viral-induced apoptosis in vertebrate lymphocytes are not uncommon (e.g. rabies, human immunodeficiency virus, feline leukemia virus, avian influenza virus, chicken anemia virus [Thoulouze et al. 1997] and human influenza virus [Mori et al. 1995]). It has not been previously reported for a penaeid shrimp virus, although Anggraeni \& Owens (1998) have reported a high prevalence of apoptotic cells within LOS. By whatever mechanism, this process suggests that de-

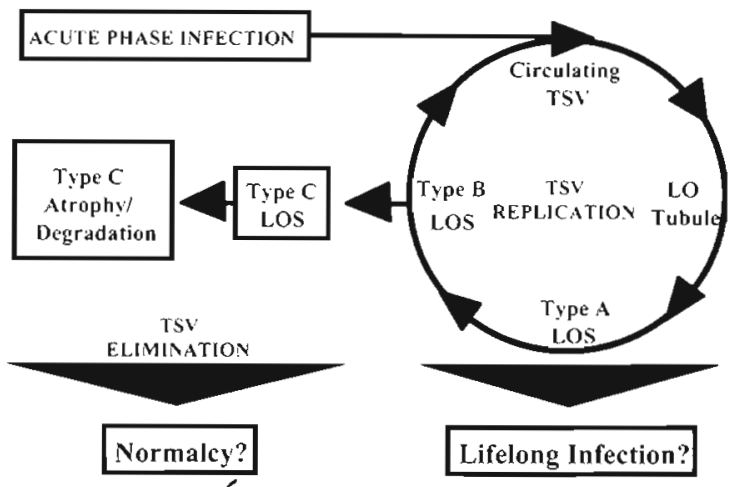

Fig. 6. Hypothesized chronic phase TSV cycle in experimentally infected Penaeus vannamei juveniles. During the acute phase of infection, TSV is released into the host circulatory system and sequestered by phagocytic cells within normal LO tubules (transition phase). These cells may either transform in situ and/or migrate and aggregate within LO hemal sinuses, initiating LOS development, beginning with the Type A form. Viral replication within the Type A LOS results in the formation of the Type B morphotype. Release of TSV into the circulatory system from Type B LOS re-initiates the LOS cycle and results in a steady-state chronic infection. In a concurrent, competing process, the virus is eliminated by Type C LOS as they degenerate, and this promotes a return to LO normalcy. Viral persistence or elimination will depend upon the balance between these competing processes generation of Type C LOS would return the LO and shrimp host to normalcy. Ultrastructural and genomic DNA analyses of late-stage chronically infected Penaeus vannamei would be needed to confirm or refute this hypothesis.

The final outcome of chronic phase TSV infections would depend upon competition between the above 2 processes, in which viral replication and elimination would occur concurrently (Fig. 6). Which process dominates in chronically infected shrimp would probably depend upon the host's overall nutritional and health status. This may explain why the prevalence of Type $C$ LOS was high while detectable TSV was low (Tables 1 \& 2) during Interval 3. By that time, the shrimp population density had been greatly reduced by mortality and sampling so that any stress from crowding and feed competition would have been alleviated.

Ectopic spheroids were detected in 6 of $56(-10 \%)$ test shrimp and 2 were found to be TSV-positive by gene probe analysis. They were observed as foci in appendages that normally contained tegmental glands (Fig. 5) and were morphologically indistinguishable from the Type A and B LOS. Ectopic spheroids have been reported in Penaeus monodon and $P$. pennicillatus from Taiwan (Lightner et al. 1987), P. monodon from Australia (Owens et al. 1991), P. stylirostris from Tahiti (Owens et al. 1991) and P. monodon from Indonesia (Christofilogiannis 1993, Turnbull et al. 1994). They have been documented from gills, heart, nerve cord, gonads, muscle, antennal gland, hepatopancreas and tegmental glands. Lightner et al. (1987) noted a correlation between the presence of both ectopic and LOS in shrimp with chronic inflammatory infections. The general hypothesis advanced was that they were hyperplastic cellular masses that had disassociated from the LO and metastasized to other sites. Although individual spheroids were observed in close proximity to the LO in a few of our chronically infected test shrimp, no histological evidence was found to indicate that TSV-induced LOS migrated to other locations. Rather, they appeared to develop de novo at sites that previously contained tegmental glands. Although ectopic spheroids have been reported in several species of penaeid shrimp, the present investigation is the first in which both LOS and ectopic spheroids were experimentally induced by viral exposure and monitored over time by gene probe analysis. Little information has been published concerning the physiology of the penaeid shrimp tegmental gland, and the reason why TSV-induced ectopic spheroids appear to develop in their location or directly from them is unknown.

To summarize our findings and our review of the literature, we speculate that both LOS and ectopic spheroids are composed of the same unique phagocytic cell type, which becomes activated and either 
forms aggregates in situ and/or migrates to infected sites as a defensive response to chronic viral infections or to other non-self substances that are too small to elicit hemocytic nodule formation (encapsulation). This hypothesis allows for a reasonable explanation of the morphological changes and gradual reduction in viral load observed within the LOS of our test shrimp. It can also explain the appearance of ectopic spheroids in multiple tissue types for shrimp diseases described by other investigators. This expands upon the hypothesis that the penaeid LO plays an important immunodefensive role (Kondo et al. 1994) by shedding some light on the role of LO tubules and LOS and by including ectopic spheroids. Clearly these structures play a relatively unexplored but significant role in the cellmediated immune response of penaeid shrimp, and they warrant further investigation.

As LOS and ectopic spheroids develop with a variety of viral infections, a definitive diagnosis of their etiology cannot be made by routine histology; virusspecific gene probes are required. Here, a probe showed that TSV could be detected in grossly normal Penaeus vannamei for at least 32 wk following an acute phase infection (Table 2, Figs. 1 \& 4). Together with the reports on infectious TSV in hemolymph for at least $1 \mathrm{yr}$ after acute infection (Dr Jeff Lotz \& Bonnie Poulos pers. comm.), these collective findings satisfy the definition of a chronic infection. This is significant from a shrimp management standpoint, because TSV survivors left in ponds or present in shrimp farm waterways are a potential source of renewed TSV outbreaks.

Acknowledgements. Support for this investigation was through grants from the Gulf Coast Research Laboratory Consortium Marine Shrimp Farming Program, CSREES, US Dept. of Agriculture (grant no 95-38808-1424), the National Sea Grant Program, US Dept. of Commerce, NOAA (grant no. NA56FD0621), and by the National Fisheries Institute

\section{LITERATURE CITED}

Anggraeni M (1999) The nrigin and role of lymphoid organ spheroid cells in the giant tiger prawn, Penaeus monodon. Masters thesis, James Cook University, Townsville

Anggraeni M, Owens L (1998) Evidence for the haemocytic origin of lymphoidal spheroids in Penaeus monodon. In: Flegel TW (ed) Advances in shrimp biotechnology. National Center for Genetic Engineering and Biotechnology, Bangkok, p 137

Bell TA, Lightner DV (1987) IHHN disease of Penaeus stylirostris: effects of shrimp size on disease expression. J Fish Dis 10:165-170

Bell TA, Lightner DV (1988) A handbook of normal penaeid shrimp histology. World Aquaculture Society, Baton Rouge, LA

Bonami JR, Lightner DV, Redman RM, Poulos BT (1992) Partial characterization of a togavirus (LOVV) associated with histopathological changes of the lymphoid organ of penaeid shrimps. Dis Aquat Org 14:145-152

Bonami JR, Hasson KW, Mari J. Poulos BT, Lightner DV (1.997) Taura syndrome of marine penaeıd shrimp: characterization of the viral agent. J Gen Virol 78:313-319

Brock JA, Gose RB, Lightner DV, Hasson KW (1995) An overview on Taura syndrome, an important disease of farmed Penaeus vannamei. In: Browdy $\mathrm{CL}$, Hopkins JS (eds) Swimming through troubled water, Proceedings of the special session on shrimp farming, Aquaculture '95. World Aquaculture Society, Baton Rouge, LA, p 84-94

Brock JA, Gose RB, Lightner DV, Hasson KW (1997) Recent developments and an overview of Taura syndrome of farmed shrimp in the Americas. In: Flegel TW, MacRae IH (eds) Diseases in Asian aquaculture III. Fish health section, Asian Fisheries Society, Manila, p 275-283

Christofilogiannis $P$ (1993) Studies on lymphoid organ pathology and related diseases in Penaeus monodon Fabricus. Masters thesis, Institute of Aquaculture, University of Stirling

Cotran RS, Kumar V, Robbins SL (1989) Inflammation and repair. In: Saunders WB (ed) Robbins pathologic basis of disease, 4 th edn. Harcourt Brace Jovanovich Inc, Philadelphia, PA, p 39-86

Flegel TW, Fegan DF, Kongsom S, Vuthikornudomkit S, Sriurairatana S, Boonyaratpalin S, Chantanachookin C, Vickers JE, Macdonald OD (1992) Occurrence, diagnosis and treatment of shrimp diseases in Thailand. In: Fulks W, Main KL (eds) Diseases of cultured penaeid shrimp in Asia and the United States. The Oceanic Institute, Honolulu, p $57-112$

Hasson KW (1998) Taura syndrome in marine penaeid shrimp: discovery of the viral agent and disease characterization studies. PhD dissertation. University of Arizona, Tucson

Hasson KW, Lightner DV, Poulos BT, Redman RM, White BL, Brock JA, Bonami JR (1995) Taura syndrome in Penaeus vannamei: demonstration of a viral etiology. Dis Aquat Org 23:115-126

Hasson KW, Hasson J, Aubert H, Redman RM, Lightner DV (1997) A new RNA-friendly fixative for the preservation of penaeid shrimp samples for virological detection using cDNA genomic probes. J Virol Methods 66:227-236

Hasson KW, Lightner DV, Mohney LL, Redman RM, Poulos BT, Mari J, Bonami JR, Brock JA (1999a) The geographic distribution of Taura syndrome virus (TSV) in the Americas: determination by histopathology and in situ hybridization using TSV-specific cDNA probes. Aquaculture 171:13-26

Hasson KW, Lightner DV, Mohney LL, Redman RM, Poulos BT, White BM (1999b) Taura syndrome virus (TSV) lesion development and the disease cycle in the Pacific white shrimp Penaeus vannamei. Dis Aquat Org 36:81-93

Kondo M, Itami T, Takahashi Y, Fuji R, Tomonga S (1994) Structure and function of the lymphoid organ in the Kuruma prawn. Dev Comp Immunol 18(Suppl1)1:1-109

Lightner DV (1996) A handbook of shrimp pathology and diagnostic procedures for diseases of cultured penaeid shrimp. World Aquaculture Society, Baton Rouge, LA

Lightner DV, Hedrick RP, Fryer JL, Chen SN, Liao IC, Kou GH. (1987) A survey of cultured penaeid shrimp in Taiwan for viral and other important diseases. Fish Pathol 22(3): $127-140$

Lightner DV, Redman RM1, Hasson KW, Pantoja CR (1995a) Taura syndrome in Penaeus vannamei: histopathology and ultrastructure. Dis Aquat Org 21:53-59

Mari J, Bonami JR, Lightner DV (1998) Taura syndrome of penaeid shrimp: cloning of viral genome fragments and 
development of specific gene probes. Dis Aquat Org 33: $11-17$

Martin GG, Hose J, Kim JJ (1987) Structure of hematopoietic nodules in the Ridgeback Prawn, Sicyonia ingentis: light and electron microscopic observations. J Morphol 192:193-204

Martin GG, Hose J, Minka G, Rosenberg S (1996) Clearance of bacteria injected into the hemolymph of the ridgeback prawn, Sicyonia ingentis (Crustacea:Decapoda): role of the hematopoietic tissue. J Morphol 227:227-233

Mori I, Komatsu T, Takeuchi K, Nakakuki K, Sudo M, Kimura $Y(1995)$ In vivo induction of apoptosis by influenze virus. $J$ Gen Virol 76:2869-2873

Nadala ECB, Lu Y, Loh PC, Brock JA (1992) Infection of Penaeus stylirostris (Boone) with a rhabdovirus isolated from Penaeus sp. Gyobyo Kenkyu 27:143-147

Oka M (1969) Studies of Penaeus orientalis Kishnouye-VIII: structure of the newly found lymphoid organ. Bull Jpn Soc Sci Fish 35(3): 245-250

Owens L, De Beer S, Smith J (1991) Lymphoidal parvoviruslike particles in Australian penaeid prawns. Dis Aquat Org 11:129-134

Perez Farfante I, Kensley BF (1997) Penaeoid and sergestoid shrimps and prawns of the world: keys and diagnoses for the families and genera. Mem Mus Natl Hist Nat 175(0): $1-233$

Editorial responsibility: Timothy Flegel,

Bangkok, Thailand
Pruder GD, Brown CL, Sweeney JN, Carr WH (1995) High health shrimp systems: seed supply, theory and practice. In: Browdy CL, Hopkins JS (eds) Swimming through troubled water, Proceedings of the special session on shrimp farming. World Aquaculture Society, Baton Rouge, LA, p 40-52

Spann KM, Vickers JE, Lester RJ (1995) Lymphoid organ virus of Penaeus monodon from Australia. Dis Aquat Org 23:127-134

Takahashi Y, Itami T, Kondo M (1995) Immunodefense system of crustacea. Fish Pathol 30(2):141-150

Thompson CB (1995) Apoptosis in the pathogenesis and treatment of disease. Science 267:1456-1462

Thoulouze MI, Lafage M, Montano-Hirose JA, Lafon M (1997) Rabies virus infects mouse and human lymphocytes and induces apoptosis. J Virol 71:7372-7380

Turnbull JF, Larkins PE, McPadden C, Matondang R (1994) A histopathological disease survey of cultured shrimp in Northeast Sumatera, Indonesia. J Fish Dis 17:57-65

Wyban JA, Swingle JS, Sweeney JN, Pruder GD (1992) Development and commercial performance of high health shrimp using specific pathogen free (SPF) broodstock Penaeus vannamei. In: Wyban JA (ed) Proceedings of the special session on shrimp farming. World Aquaculture Society, Baton Rouge, LA, p 254-259

Submitted: December 24, 1998; Accepted: August 8, 1999 Proofs received from author(s): October 28, 1999 